\title{
EVALUATION OF IMMUNE RESPONSE AGAINST REDUCED DOSE OF Brucella abortus STRAIN 19 VACCINE ADMINISTERED THROUGH CONJUNCTIVAL ROUTE IN CATTLE
}

\author{
Chaithra $\mathrm{Y}^{1}$, Isloor $\mathrm{S}^{1^{*}}$, Shivaram $\mathrm{B}^{2}$, Suryaprasad $\mathrm{V}^{2}$, Sharada $\mathrm{R}^{1}$, Rathnamma $\mathrm{D}^{1}$, Srinivas $\mathrm{K}^{2}$, \\ Veeregowda $\mathrm{BM}^{1}$, Narayanaswamy $\mathrm{HD}^{3}$, Shome $\mathrm{BR}^{4}$, Kundan $\mathrm{SP}^{2}$
}

\author{
${ }^{1}$ Department of Microbiology, Veterinary college, KVAFSU, Hebbal, Bangalore-560 024 \\ ${ }^{2}$ Indian Immunologicals Ltd., Gachibowli, Hyderabad-500 032 \\ ${ }^{3}$ Hon'ble Vice Chancellor, KVAFSU, Bidar-585401 \\ ${ }^{4}$ ICAR-National Institute of Veterinary Epidemiology and Disease Informatics, Ramagondanahalli, Yelahanka, Bangalore-560 064
}

Received - December 03, 2017; Revision - February 09, 2018; Accepted - June 30, 2018

Available Online - August 10, 2018

DOI: http://dx.doi.org/10.18006/2018.6(4).739.745

\author{
KEYWORDS \\ Brucellosis \\ Conjunctival vaccine \\ Immune response \\ Cattle
}

\begin{abstract}
A study was undertaken to evaluate the immune response against Brucella abortus S19 reduced dose vaccine administered through conjunctival route in comparison with B. abortus S19 standard dose administered through subcutaneous (S/C) route. All, 38 Brucella seronegative cattles were grouped as Group 1 with 24 animals (>8 months), Group 2 with 8 female calves (4-8 months), Group 3 with 6 animals (>8 months). On day 0, Group 1, 2 and 3 animals were administered with reduced dose (5$8 \times 10^{9} \mathrm{CFU} /$ dose $)$ vaccine through conjunctival route, standard dose $\left(40-80 \times 10^{9} \mathrm{CFU} / \mathrm{dose}\right)$ vaccine through $\mathrm{S} / \mathrm{C}$ route and normal saline through conjunctival route respectively. Blood and serum samples were collected on $0,21,60,90,120,150$ and 180 Day of post vaccination (DPV). On $120^{\text {th }}$ day, Group1 animals received booster conjunctival vaccine dose $\left(5-8 \times 10^{9} \mathrm{CFU} / \mathrm{dose}\right)$. The humoral and cell mediated immune (CMI) response induced by conjunctival and $\mathrm{S} / \mathrm{C}$ route vaccine was determined by Competitive Enzyme Linked Immuno Sorbant assay (C-ELISA) and Interferon- $\gamma$ (IFN- $\gamma$ ) assay respectively. The vaccinal antibodies on 21, 60, 90, 120, 150 and 180 DPV were 33.3, 41.6, 17.3, 22.7, 77.2 and 70.1\% respectively in conjunctival group and $100,100,87.5,50,33.3$ and $30.2 \%$ respectively in S/C route vaccine group. Stimulation index (>8.89) for IFN- $\gamma$ response on 21, 60, 90, 120150 and 180 DPV were
\end{abstract}

* Corresponding author

E-mail: kisloor@gmail.com (Dr. Shrikrishna Isloor)

Peer review under responsibility of Journal of Experimental Biology and Agricultural Sciences.

Production and Hosting by Horizon Publisher India [HPI] (http://www.horizonpublisherindia.in/).

All rights reserved.
All the article published by Journal of Experimental Biology and Agricultural Sciences is licensed under a Creative Commons Attribution-NonCommercial 4.0 International License Based on a work at www.jebas.org.

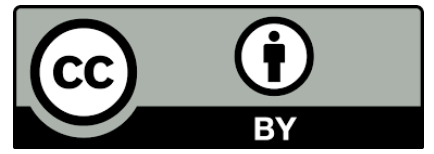


$25,70.8,52.1,50,69.5$ and $20 \%$ respectively in conjunctival group and 37.5, 37.5, 25, 50, 33.3 and $16.7 \%$ respectively in S/C vaccine group. The CMI response was comparatively high on 60 DPV in conjunctival group compared to S/C group animals. Humoral immune response of S/C group animals was $100 \%$ on 21 and 60 DPV. After administration of the booster dose vaccinal antibodies increased from 22.7 to $77.2 \%$ and stimulation index for IFN- $\gamma$ response from 50 to $69.5 \%$. Conjunctival route vaccination is safer and easier to dispense than S/C route and it is effective in female cattle $>8$ months of age. Persistent antibody level is a disadvantage in S/C vaccine which can be overcome by using reduced dose conjunctival route vaccine. If a calf misses S/C vaccination in the age group of 4-8 months an alternate way to immunize animals through conjunctival vaccine can be adopted to achieve maximum vaccination coverage against brucellosis.

\section{Introduction}

The main causative agent of brucellosis in cattle is Brucella abortus, it causes abortion and infertility in adult animals (Corbel et al., 2006). It is one of the highly contagious and economically important ubiquitous reproductive disease of dairy animals and highly prevalent among bovine population of the country (Patel et al., 2014). B. abortus strain 19 is a live attenuated vaccine and it is used extensively for vaccination against bovine brucellosis on female calves between three to eight months of age (Manthei, 1959). The main disadvantage of $S 19$ vaccine is restriction on age of the animals, the agglutinin titres following vaccination with $B$. abortus S19 vaccine cannot be distinguished from those that result after infection (King \& Frank, 1961; Lin \& Ficht, 1995). Other limitations of subcutaneous vaccinations have been adverse effects such as abortions in pregnant animals and persistency of vaccinal antibodies. However, such adverse effects have not been reported by Chand et al. (2014) on vaccination of adult animals by conjunctival route with a reduced dose of B. abortus S19 vaccine. Furthermore, report of OIE (2016), the administration of reduced dose of vaccine by subcutaneous route in case of young and adult animals resulted in prolonged persistence of vaccinal antibodies in large population of Rev.1 vaccinated animals that creates serious interferences in the serological diagnosis of brucellosis. Conjunctival vaccination minimizes these problems (particularly when the upper limit of age for vaccination is 5 months) and thus it is the method of choice for combined eradication programmes.

Considering the above facts in view, the present study was undertaken with the objectives to study the cell mediated and humoral immune response of reduced dose of B. abortus Strain 19 vaccine administered through conjunctival route in cattle. Further, cell mediated and humoral immune response of regular dose of $B$. abortus strain 19 vaccine administered through $\mathrm{S} / \mathrm{C}$ route in female calves and persistence of $B$. abortus Strain 19 vaccinal antibodies due to conjunctival and $\mathrm{S} / \mathrm{C}$ route vaccination in cattle was also studied.

\section{Materials and Method}

Proposal was submitted to the Institutional Animal Ethics Committee (IAEC) and was approved vide No. LPM/IAEC/177/2013 dtd 25.09.2013. The blood and serum samples of cattle were collected from Bengaluru Gorakshana Goshala, Doddanekkundi, Bengaluru.

\subsection{Selection of animals}

Brucella seronegative cattle were selected based on Rose Bengal Plate Test (RBPT) and Competitive Enzyme Linked Immuno Sorbant Assay (C-ELISA) from the organized farm by using AHVLA kit method

\subsection{Study vaccine}

Brucella abortus S19 reduced dose vaccine of $5 \times 10^{9}$ to $8 \times 10^{9}$ $\mathrm{CFU}$ organisms were administered through conjunctival route. A standard vaccine dose of $40 \times 10^{9}$ to $80 \times 10^{9} \mathrm{CFU}$ viable organisms were administered through $\mathrm{S} / \mathrm{C}$ route. Both the vaccines used in the present study were procured by Indian Immunological Ltd. (IIL), Hyderabad.

\subsection{Experimental design}

Animals were broadly grouped in three groups viz. Group 1 -3. Among these, group-1 consists 24 animals (more than eight months age irrespective of breed and stage of lactation) and had a vaccine dose of $5 \times 10^{9}$ to $8 \times 10^{9} \mathrm{CFU} /$ which was administered through conjunctival route. The booster dose was administered on 120th day. While group 2 have eight female calves (four- eight months age) those are vaccinated with dose of $40 \times 10^{9}$ to $80 \times 10^{9} \mathrm{CFU} /$ dose was administered through S/C route. Group 3 contain only six animals (more than eight months age irrespective of breed and stage of lactation). This group was placebo group and received only normal saline through conjunctival route. 


\subsection{Rose Bengal Plate Test (RBPT)}

Rose Bengal colored antigen was procured from the Institute of Animal Health and Veterinary Biologicals (IAH and VB), Bengaluru. The antigen comprises of B. abortus S99 smooth 11 per cent cell suspension buffered to a low $\mathrm{pH}$, usually $3.65 \pm 0.05$. On a clean microscopic slide, equal volume $(30 \mu 1)$ of antigen and test serum sample were mixed thoroughly by tip of the micropipette and rotated gently for $3 \mathrm{~min}$ at RT. Immediately after 3 min of incubation results were recorded as positive or negative based on the presence or absence of agglutination, respectively.

\subsection{Interferon- $\gamma$ Release Assay}

\subsubsection{Sample collection and processing for IFN- $\gamma$ assay}

Whole blood samples were collected from jugular vein of animals using 18 gauge needle attached to a vacutainer coated with heparin (Beckton Dickinson, Cat. No. 367874). on 0, 21 ${ }^{\text {st }}, 60^{\text {th }}$, $90^{\text {th }}, 120^{\text {th }}, 150^{\text {th }}$ and $180^{\text {th }}$ day. One $\mathrm{ml}$ of blood sample was added in 24 well cell culture plates in pre-determined format (Nunc, Denmark, Cat. No.142475). Blood sample each in duplicate, were stimulated with heat killed antigen of B.abortus S19 and B.abortus 544 at $10 \mu 1$ concentration i.e. B. abortus S19 at $40 \mu \mathrm{g} / 10 \mu \mathrm{l}$ and B. abortus 544 at $10 \mu \mathrm{g} / 10 \mu \mathrm{l}$ concentration of protein content diluted in PBS (pH 6.4) at $100 \mu 1 / \mathrm{ml}$ of blood/well. Blood samples were also stimulated with pokeweed mitogen lectin from Phytolacca americana (Sigma-Aldrich, Cat. No.L9379-10MG) $8 \mu \mathrm{l} / \mathrm{ml}$ of blood / well at concentration of $1 \mu \mathrm{g}$ / $\mathrm{ml}$ of distilled water and PBS $100 \mu \mathrm{l} / \mathrm{ml}$ of blood / well as positive and negative controls, respectively. The 24 well plates were incubated in humidifier chamber at $37^{\circ} \mathrm{C}$ with 5 per cent $\mathrm{CO}_{2}$ for $24 \mathrm{~h}$ and Plasma samples were collected after $24 \mathrm{~h}$ by manual pipetting and stored at $-20^{\circ} \mathrm{C}$ till processed for standard ELISA for interferon $\gamma$.

The Sandwich ELISA was employed to detect IFN- $\gamma$ derived from whole blood stimulated plasma samples. ELISA plates were coated with 1:2000 diluted monoclonal capture antibody CC330 $\left(100 \mu 1 /\right.$ well) diluted in PBST and incubated overnight at $4^{\circ} \mathrm{C}$. Unbound antibody washed thrice using washing buffer (PBST). Blocking buffer $(200 \mu \mathrm{l} /$ well) was added to all the wells and kept on the plate shaker (500-600) for $1 \mathrm{~h}$ at RT and this was followed by three washing of PBST. Antigen standard was prepared ranging from $1000 \mathrm{pg} / \mathrm{ml}$ to $4 \mathrm{pg} / \mathrm{ml}$ and added in respective wells (100 $\mu 1$ / well). Plasma samples were added to respective wells

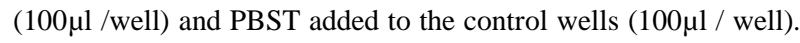
The plates were incubated for $1 \mathrm{~h}$ on the plate shaker at RT and washed thrice with PBST. Biotinylated antibody was prepared at 1: 4000 dilution and added $100 \mu \mathrm{l} /$ well. The plates were incubated at RT for $1 \mathrm{~h}$ on the plate shaker and this was followed by the three time washing of plate with PBST. Streptavidin HRP was prepared at 1:8000 dilution and added $100 \mu \mathrm{l} /$ well. The plates were incubated at RT for $1 \mathrm{~h}$ on the plate shaker and the plate washed thrice with PBST. Substrate solution was prepared by dissolving one TMB tablet in $10 \mathrm{ml}$ of substrate buffer followed by addition of $3 \mu \mathrm{l}$ of $30 \% \mathrm{H}_{2} \mathrm{O}_{2}$. The solution was added at $100 \mu \mathrm{l} /$ well and the plates were incubated at RT for $30 \mathrm{~min}$ on the plate shaker. After $30 \mathrm{~min}$, color reaction was stopped by adding $0.18 \mathrm{M} \mathrm{H}_{2} \mathrm{SO}_{4}$ at $100 \mu \mathrm{l} /$ well. Optical density of the wells was measured at $450 \mathrm{~nm}$.

\section{SI $=\frac{\text { Sample OD }- \text { Blank OD }}{\text { Sample PBS OD }- \text { Blank OD }}$}

Cut off was taken based on the formula: Mean $+2 \times$ SD (Standard deviation)

\subsubsection{Competitive Enzyme Linked Immuno Sorbent Assay}

Blood was collected on $0,21^{\text {st }}, 60^{\text {th }}, 90^{\text {th }}, 120^{\text {th }}, 150^{\text {th }}$ and $180^{\text {th }}$ day with sterile 18 gauge needle and vacutainers ( $9 \mathrm{ml}$, capacity) without anticoagulant and allowed to clot for 30 minutes, before transportation to laboratory on ice. The separated serum was stored at $-20^{\circ} \mathrm{C}$ in aliquots with proper label till further use. Competitive ELISA was performed using AHVLA kit method for the collected serum samples.

\section{Results}

This study was undertaken to evaluate the safety and immunogenicity of $B$. abortus S19 reduced dose vaccine administered through conjunctival route in comparison with of $B$. abortus S19 standard dose vaccine administered through S/C route.

\subsection{Selection of animals}

Based on the result of RBPT, out of 70 studied animals, 50 seronegative animals were selected. Competitive ELISA was performed using AHVLA kit method for 50 seronegative animals which were seronegative by RBPT. Based on result of C-ELISA, we selected 38 seronegative animals out of 50 for the study.

\subsection{Safety Evaluation}

Safety evaluation was done by observing and recording the adverse events during the first $30 \mathrm{~min}$ to $1 \mathrm{~h}$ after vaccination. The animals were observed for local pain, swelling, rashes, skin eruption, redness at administration site, induration, fever, loss of appetite, restlessness and unsolicited systemic events etc. No serious adverse events were recorded in the study. 


\subsection{Evaluation of the efficacy of vaccination}

\subsubsection{Humoral Immune Response by C-ELISA}

The humoral immune response induced by B. abortus S19 reduced dose conjunctival route vaccine was determined by Competitive ELISA using AHVLA kit. Below or equal to 60 per cent of conjugate control OD value was considered as positive. Above 60 per cent of conjugate control OD value was considered as negative. In reduced dose conjunctival vaccine group, the percentage of responders on 21 and 60 DPV were 33.3 and 41.6 per cent respectively. Subsequently, the percentage of responders increased to 77.2 per cent on $150 \mathrm{DPV}$ after administering the booster dose (Table 1). Whereas in standard dose $\mathrm{S} / \mathrm{C}$ route vaccinated group, the percentage of responders was 100 percent in both 21 and 60 DPV. Thereafter, the percentage of responders was reduced at 90, 120, 150 and $180 \mathrm{DPV}$ (Table 1).

\subsubsection{Cell Mediated Immune Response by IFN - gamma assay}

The cell mediated immunity was determined by Interferon- $\gamma$ assay with Sandwich ELISA, a useful method to reveal the presence of immune response following lymphocyte stimulation with heat killed B. abortus S19 and 544 (Plate 1). The interferon- $\gamma$ assay results were expressed as percentage responders based on stimulation indices (SI), calculated as the ratio between the mean OD value of IFN- $\gamma$ from blood cells stimulated with specific antigen at $450 \mathrm{~nm}$ and the mean optical density values of IFN- $\gamma$ from blood cells stimulated with PBS control as described by Weynants et al. (1995). Two cut-off values 8.89 and 9.26 were obtained when the blood samples were stimulated against $B$. abortus S19 and 544 respectively. The samples exhibiting above the cut off values were considered as responders for CMI.

The IFN- $\gamma$ response induced by $B$. abortus S19 reduced dose conjunctival vaccine as determined by sandwich ELISA titre indicated that by $21 \mathrm{DPV}, 25$ per cent of the cattle responded to the B. abortus S19 heat killed antigen. After administration of booster dose on $120 \mathrm{DPV}$, percent of responders increased from 50 per cent to 69.5 per cent (Table 2). Similar findings were observed in group of animals stimulated with B. abortus 544 antigen (Table 3). However, almost all the animals responded for the reduced dose conjunctival route vaccine. The control group cattle remained unresponsive throughout the trial period for both the antigens.

\section{Discussion}

As control of bovine brucellosis is concerned, currently, $B$. abortus S19 vaccine is being used in most of the countries in female calves in the age group of 4-8 months. Serological evidence suggested that brucellosis is endemic in most parts of India (Isloor et al., 1998; Renukaradhya et al., 2002; Khurana et
Table 1 Per cent positive animals for humoral immune response at different intervals after vaccination

\begin{tabular}{|c|c|c|c|c|c|c|c|}
\hline \multicolumn{1}{|c|}{ Group } & 0 & 21 & 60 & 90 & 120 & 150 & 180 \\
\hline Conjunctival & 0 & 33.3 & 41.6 & 17.3 & 22.7 & 77.2 & 70.1 \\
\hline Subcutaneous & 0 & 100 & 100 & 87.5 & 50 & 33.3 & 30.2 \\
\hline Control & 0 & 0 & 0 & 0 & 0 & 0 & 0 \\
\hline
\end{tabular}

Table 2 IFN- $\gamma$ response against heat killed B. abortus S19 antigen in B. abortus $\mathrm{S} 19$ reduced dose Conjunctival, Standard dose S/C and Control groups

\begin{tabular}{|c|c|c|c|c|c|c|c|}
\hline \multicolumn{1}{|c}{ Group } & 0 & 21 & 60 & 90 & 120 & 150 & 180 \\
\hline Conjunctival & 0 & 25 & 70.8 & 52.1 & 50 & 69.5 & 20 \\
\hline Subcutaneous & 0 & 37.5 & 37.5 & 25 & 50 & 33.3 & 16.7 \\
\hline Control & 0 & 0 & 0 & 0 & 0 & 0 & 0 \\
\hline
\end{tabular}

Table 3 IFN-Gamma response against heat killed B. abortus 544 antigen in B. abortus S19 reduced dose Conjunctival, Standard dose S/C and Control groups

\begin{tabular}{|c|c|c|c|cc|c|c|}
\hline & \multicolumn{7}{|c|}{ DPV } \\
Group & 0 & 21 & 60 & 90 & 120 & 150 & 180 \\
\hline Conjunctival & 0 & 41.6 & 62.5 & 52 & 45 & 52 & 20 \\
\hline Subcutaneous & 0 & 50 & 37.5 & 25 & 50 & 33.3 & 16.7 \\
\hline Control & 0 & 0 & 0 & 0 & 0 & 0 & 0 \\
\hline
\end{tabular}

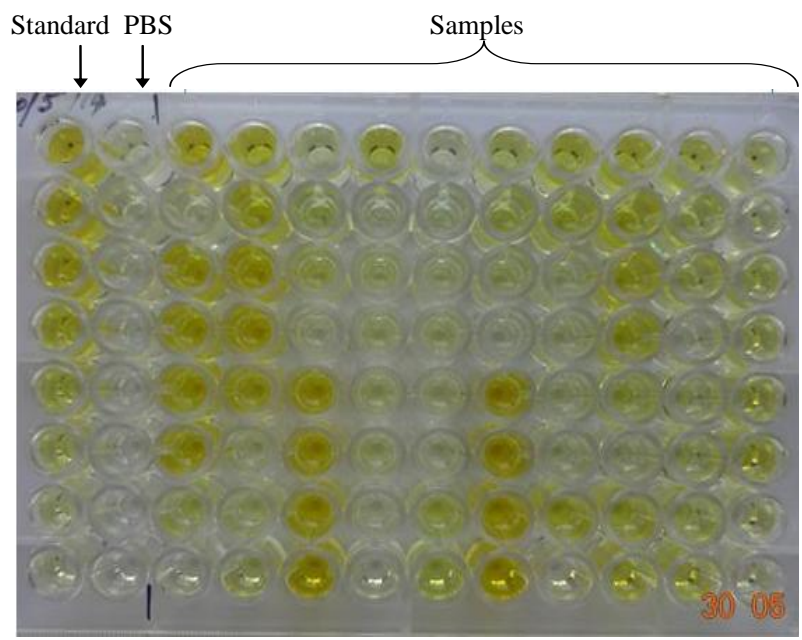

Plate 1 Plate layout of IFN- $\gamma$ assay (Sandwich ELISA) for plasma samples. 
al., 2012; Shome et al., 2014). In a country like India, where there is a ban on test and slaughter programme, vaccination serves as the only means of disease control which will reduce the number of positive reactors in a herd.

In the present study, seronegative cattle $(n=50)$ as detected by RBPT in an organized farm were selected. Further, C-ELISA, detected only 38 out of 50 RBPT negative serum samples to be negative. The C-ELISA being more sensitive than RBPT identified 12 out of 50 RBPT based seronegatives to be brucella positive. In view of this, all the 38 RBPT and C-ELISA based brucella seronegative samples were included in the study. Guarino et al. (2001) found that ELISA was more effective in detection of infection than RBPT because sensitivity of ELISA is higher than RBPT. Animals of the age $>8$ months and 4-8 months were selected for conjunctival and $\mathrm{S} / \mathrm{C}$ vaccine respectively.

\subsection{Cell Mediated Immune Response by IFN - gamma assay}

Protective immunity against brucellosis involves both humoral and CMI responses (Nicoletti, 1990). Lymphocyte proliferation and cytokine detection assays are the most widely used correlates of CMI responses. A useful method to reveal the presence of CMI response against $B$. abortus can be the detection of Interferon- $\gamma$ production following lymphocyte stimulation with the specific antigen. The test utilizes, in vitro, the same mechanism that can be evoked in vivo by the brucellin skin test. Previous studies conducted on this topic demonstrated that Brucella species is able to elicit a macrophage response through the production of IFN- $\gamma$ by stimulated T lymphocytes both in mice (Jones \& Winter, 1992) and in cattle infected with B. abortus (Weynants et al., 1995).

The CMI response against B. abortus $\mathrm{S} 19$ and 544 studied by IFN- $\gamma$ assay revealed a good response in the group of animals where reduced dose vaccine was used. The IFN- $\gamma$ response was comparatively high on $60 \mathrm{DPV}$ in reduced dose conjunctival route group animals in comparison with the animals in the standard dose S/C route group indicating good CMI response which is pivotal in controlling and eliminating intracellular pathogens like Brucella. From 60 to $120 \mathrm{DPV}$ (Table $2 \& 3$ ), the percentage responders drastically reduced. None of the control animals were reported positive. Odbileg et al. (2008) observed increased level of IFN- $\gamma$ during $1^{\text {st }}$ week and reduced level of IFN- $\gamma$ on $2^{\text {nd }}$ and $3^{\text {rd }}$ week after vaccination with B. abortus S19 reduced dose S/C route vaccine. However, titres increased on 150 DPV due to the administration of booster on 120 DPV. Interferon- $\gamma$ response against heat killed B.abortus 544 also showed similar results as that of IFN- $\gamma$ response against heat killed B.abortus S19 antigen.

Conjunctival administration of live vaccines was shown to induce good IFN- $\gamma$ response but low serological responses (Plommet \&
Fensterbank, 1976; Plommet \& Fensterbank, 1979; Fensterbank et al., 1985; Fensterbank et al.,1987).

\subsection{Humoral Immune Response by C-ELISA}

The humoral immune response induced by B. abortus S19 reduced dose conjunctival route vaccine was determined by Competitive ELISA using AHVLA kit. The humoral immune response of conjunctival vaccine was comparable with that of standard dose vaccine after booster dose at the end of the study indicating the good response to booster dose. Plommet \& Fensterbank (1976) demonstrated that vaccination of adult animals with reduced dose of S19 vaccine by conjunctival route did not induce persistent antibody titers, and the level of protection achieved was comparable to that of a standard dose given by S/C route. In humoral immune response, B. abortus S19 standard dose $\mathrm{S} / \mathrm{C}$ route vaccine group revealed higher percentage of responders. It was 100 per cent for both 21 and 60DPV. After $60 \mathrm{DPV}$, the percentage of responders drastically reduced. Whereas, B. abortus $\mathrm{S} 19$ reduced dose conjunctival route vaccine drastically increased the percentage of responders on $150 \mathrm{DPV}$ after inoculation of the booster dose on 120 DPV. The control cattle remained unresponsive throughout the study period (Table 1). In this study, the vaccination by $\mathrm{S} / \mathrm{C}$ route with standard dose produced 100 percent seroconversion. In the low dose conjunctival vaccine group, there was less seroconversion and even after booster 100 percent seroconversion was not noticed. This could be attributed to vaccine strain colonization mostly restricted to the lymph nodes of the head in case of conjunctival vaccination (Plommet \& Fensterbank, 1976), whereas, S/C vaccination systemically extends colonization to other lymphoid organs including spleen; hence a higher serological response

Chand et al. (2014) suggested that the problem of persistent antibody titers due to subcutaneous vaccination of adult animals could be circumvented if conjunctival route is used for vaccination. Further, it was reported that vaccination of adult animals with a low dose B. abortus S19 vaccine by conjunctival route did not result in either abortion or persistancy of vaccinal antibodies, which are the major limitations in case of subcutaneously vaccinated adult animals. Furthermore, the findings of this study were in concurrence with Poster et al. (2002), who also recorded that the animals vaccinated with a reduced conjunctival dose were found to be free from detectable antibodies in less than three months post vaccination, These rapid decrease in the antibody suggested that this practice could be adopted in the campaign against brucellosis.

\section{Conclusion}

The $B$. abortus $\mathrm{S} 19$ reduced dose vaccine is safe and effective in female cattle above 8 months of age when administered through 
conjunctival route. The safety and immunogenicity study of $B$. abortus S19 reduced dose conjunctival route vaccine in cattle revealed that it was safe after conjunctival administration without any local or systemic adverse events for a period of 180 days and effective in eliciting a good CMI and humoral immune response which was comparable to that of standard dose vaccine. In a country like India, where there is a ban on test and slaughter programme, in such condition vaccination serves as the only means of disease control which will reduce the numbers of positive reactors in a herd and is directly related to the percentage of vaccinated animals. However, as for the B. abortus S19 vaccination is concerned, the age restrictions are imposed because the serological response to immunization is less prolonged in young animals and takes time to disappear before they grow old enough to need testing. The agglutinin titres following administration of B. abortus S19 vaccine cannot be distinguished from those that result after infection; a major disadvantage of $B$. abortus S19 vaccine particularly in calves vaccinated after the eighth month. But, circumstances arise when immunization of adult cattle may be advisable and these necessitate the use of reduced doses of $B$. abortus $\mathrm{S} 19$. Keeping the above in view, and as per the report of World Organization for Animal Health (OIE)2013, reduced CFU levels per dose of vaccine could be administered through the conjunctival route in adult cattle to overcome the afore mentioned drawbacks. This approach could be highly useful in controlling bovine brucellosis in areas where brucellosis is endemic.

\section{Conflict of Interest}

The authors declare that there is no conflict of interest regarding the publication of this review paper.

\section{References}

Chand P, Chhabra R, Nagra J (2014) Vaccination of adult animals with a reduced dose of Brucella abortus S19 vaccine to control brucellosis on dairy farms in endemic areas of India. Tropical Animal Health and Production 47: 29-35

Corbel MJ, Elberg SS, Cosivi O (2006) brucellosis in humans and animals. World health organization, geneva.

Fensterbank R, Pardon P, Marly J (1985) Vaccination of ewes by a single conjunctival administration of Brucella melitensis Rev 1 vaccine. Annales de recherches veterinaries 16, 351-356

Fensterbank R, Verger JM, Grayon M (1987) Conjunctival vaccination of young goats with Brucella melitensis strain Rev 1. Annales de recherches veterinaries 18: 397-403

Guarino A, Fusco G, Matteo AD, Urbani G, Condoleo R, Serepe L, Ventura MD, Gallo P (2001) Indirect ELISA for the diagnosis of brucellosis in water buffaloes (Bubalus bubalis) in Italy. Veterinary Record 149: 88-90.

Isloor S, Renukaradhya GJ, Rajasekhar M (1998) A serological survey of bovine brucellosis in India. Revue scientifique et technique 17: 781-785

Jones SM, Winter AJ (1992) Survival of virulent and attenuated strains of Brucella abortus in normal and gamma interferon activated murine peritoneal macrophages. Infection and Immunity 60: $3011-3014$

Khurana SK, Srivastava SK, Prabhudas K (2012) Seroprevalence of bovine brucellosis in Haryana by avidin-biotin serum ELISA and its comparison with RBPT and SAT. Indian Journal of Animal Science 82: 448-450

King NB, Frank NA (1961) Effect of age on resistance and retention of titer in cattle vaccinated with strain 19 Brucella abortus vaccine. Journal of the American Veterinary Medical Association 139 : 100-104.

Lin J, Ficht TA (1995) Protein synthesis in Brucella abortus induced during macrophage infection. Infection and Immunology 63: 1409-1414.

Manthei CA (1959) Summary of controlled research with strain 19, Proceedings 63rd Ann Meet US Livestock Sanitary Association.

Nicoletti PL (1990) Vaccination In: Nielsen KH, Duncan JR (Eds.) Animal brucellosis. CRC Press, Boca Raton, Florida, USA, 283-300.

Odbileg R, Purevtseren B, Gantsetseg D, Boldbaatar B (2008) Cytokine Responses in Camels (Camelus bactrianus) Vaccinated with Brucella abortus strain 19 Vaccine. The Journal of Veterinary Medical Science 70: 197-201.

OIE (World Organisation for Animal Health) 2016. Bovine brucellosis. Section 2.4.3.

Patel MD, Patel PR, Prajapati MG, Kanani AN, Tyagi KK, Fulsoundar AB (2014) Prevalence and risk factor's analysis of bovine brucellosis in peri-urban areas under intensive system of production in Gujarat. Indian Veterinary World 7: 509-516.

Plommet M, Fensterbank R (1976) Vaccination against bovine brucellosis with a low dose of strain 19 administered by the conjunctival route. iii. Serological response and immunity in the pregnant cow. Annales de recherches veterinaries $7: 9-23$

Plommet M, Fensterbank R (1979) Vaccination against bovine brucellosis with a low dose of strain 19 administered by the 
conjunctival route. iv. Comparison between two methods of vaccination. Annales de recherches veterinaries 10: 131-139

Poster FP, Ramos ET, Thiesen SV (2002) Application of EnzymeLinked Immunosorbant Assay for bovine brucellosis in Rio grande do sul, Brazil. Centro de PesquisaVeterinária“Desiderio Finamor", http://www-naweb.iaea.org/nafa/aph/public/poesterindirect-1055.pdf

Renukaradhya GJ, Isloor S, Rajasekhar M (2002) Epidemiology, zoonotic aspects, vaccination and control / eradication of brucellosis in India. Veterinary Microbiology 90: 183-195.
Shome R, Padmashree BS, Krithiga N, Triveni K, Sahay S, Shome BR, Singh P, Rahman H (2014) Bovine Brucellosis in Organized Farms of India - An Assessment of Diagnostic Assays and Risk Factors. Advances in Animal and Veterinary Sciences 2: 557-564.

Weynants V, Godfroid J, Limbourg B, Saegerman C, Letesson JJ (1995) Specific bovine brucellosis diagnosis based on in vitro antigen specific gamma interferon production. Journal of Clinical Microbiology 33: 706-71 